\title{
The Effect of Real-Time Individual Process Performance Feedback on Computer-based Group Idea Generation
}

\author{
J. H. Jung*
}

〈목 차〉

I . Introduction

ПI. Prior Studies

III. Theoretical Framework

IV. Methods
V. Results

VI. Discussions

References

\section{I . Introduction}

The creative industries - refers to a range of economic activities which are concerned with the generation or exploitation of knowledge and information - has become recognized to increasingly important to the creative economy. Landry and Bianchini (1995) stress that "[such] industries $\cdots$ will depend increasingly on the generation of knowledge through creativity and innovation," (p. 4). As such, Jung (2012, 2013) underscores the role of creativity as a foundation to achieve sustainable competitive advantage and foster successful innovation for the creative economy. Since an idea generation task, which encourages divergent thinking, has been considered the locus of creativity (McGrath, 1984), researchers across disciplines have focused on identifying better techniques to enhance the performance of idea generation and have developed numerous individual-based and group-based methods so far (Mullen, 1983). Given that computer-based group idea generation have consistently shown to perform better than individual-based idea generation for a broad range of group sizes and tasks (Valacich et al., 2006), group-based techniques are of particular interest in this study.

Researchers have often viewed that group productivity in generating ideas is contingent upon the balance between process gains and process losses (Connolly et al, 1990).

* Associate Professor, College of Economics and Business, Catholic University of Daegu, jjung@cu.ac.kr 
Accordingly, prior studies have focused on either improving the process gains (e.g., Dennis et al., 1996; Garfield et al., 2001) or mitigating the process losses (e.g., Jung, 2012, 2013) in an attempt to break the contingent balance between the gains and the losses. In essence, these gain and loss factors identified thus far are confluent to two latent process factors: cognition and motivation (Dennis et al., 1996). Cognition refers to the intrapsychic process of assimilating stimuli and producing ideas in a novel and useful way. Motivation (or effort) can be viewed as the result of social influence of group members on each other that acts to either facilitate or inhibit an individual's performance in the process (Connolly et al, 1990). Although these two factors are equally important (Paulus and Brown, 2003), Valacich et al.'s study (2006) indicates stronger effect of motivation over cognition on the outcome. To be specific, when groups were composed of high-performing individuals, there was a much greater likelihood of consistent, high-level contributions among group members. On the other hand, when groups were composed of low-performing individuals, the outcome was reverse. This implies that the optimization of cognition (either cognitive stimulation or cognitive interferencel)) depends on the perception of the magnitude of motivation by other group members (Paulus and Brown, 2003).

Expanding on the above implication, we hoped for social facilitation (positive motivation), which induces an upward comparison that participants are motivated to match the performance of the best group members (Paulus and Brown, 2003). However, all the evidence suggests social impairment (i.e., negative motivation; downward social comparison, which adjusts overall performance to the least performing members) to be more dominant in interacting brainstorming groups. To be specific, in face-to-face interaction, group members tend to adjust their performance to the level of the least proficient member (Paulus and Brown, 2003). In electronic interaction, due to the effects of random group composition and anonymity in conjunction with unregulated (i.e., unrewarded and unpunished) individual performance behavior (Jung, 2013), performance tends to regress toward the mean ${ }^{2}$ ). This leads to a speculation that if a way could be found to control social influence in the process (i.e., to discourage downward comparison and to encourage upward comparison simultaneously), it may be possible

1) Cognitive stimulation and cognitive interference are both sides of the same coin in the idea generation process (Nijstad et al, 2003). They both occur by reading the contributions of others in computer-interacting groups. The former occurs when participants are stimulated by task-relevant ideas generated by others. On the other hand, the latter occurs when the contributions of others interfere with one's train of thought.

2) The goal of group brainstorming is to generate as many quality (i.e., novel and useful) ideas as possible. This depends on high performers. In randomly composed anonymous groups, high performers tend to reduce their efforts. 
The Effect of Real-Time Individual Process Performance Feedback on Computer-based Group Idea Generation

for electronic brainstorming to become more productive. Furthermore, although it has been consistently suggested that the group interaction process holds a key to group effectiveness, motivation has been viewed as the result of the interaction process (e.g., Hackman and Morris, 1975; Steiner, 1972), rather than the process itself (McGrath, 1984). Although group interaction process refers to "all of the behavior of all of the members of an acting group $\cdots$ in action" (McGrath, 1984, p. 139), given the tendency that computer-mediated groups are more task-oriented, we focus specifically on the control of task performance behavior in an effort to improve group interaction process by borrowing the concept of process control, which is a widely used statistical method to detect changes in processes by analyzing past task behavior and by monitoring current and future task behavior on the performance. This would allow us to control and steer socio-motivational influence in a positive direction in the interaction process.

\section{Prior Studies (Jung et al., 2010; Jung, 2013)}

In computer-mediated idea generation where contributions can be anonymous, the ability to accurately monitor performances is limited (Pinsonneault and Heppel, 1998). Besides, the equality principle is used in distributing rewards after pooling contributions. Studies across disciplines (e.g., Michener and DeLamater, 1999) commonly suggest that perceived fairness (or distributive justice) - an affective and cognitive feeling about the fairness of the economic costs of the individual contributions - significantly influences attitude toward the performance behavior. Since performance information can serve as a cue to regulate appropriate behavior and as a reward (e.g., social recognition and attention) to motivate performance (Ashford and Commings, 1983), the absence of performance information undermines the critical effort-to-performance and performance-toproportional reward linkages, which are important components of an individual's motivation (Porter and Lawler, 1968). Thus, the absence of clear task performance attribution can contribute to social loafing, reducing overall task performance. However, in the context of idea generation (regardless of face-to-face or computer-based), due to its tight link to creativity (McGrath, 1984), which often stresses intrinsic rather than extrinsic motivation (Cacioppo and Petty, 1982), extrinsic motivational factors such as performance information that can also play an important role in short-term settings such as idea generation (Paulus and Brown, 2003) have been overlooked.

Our prior study (Jung et al., 2010) evidences a consistent, substantial performance gain by the provision of real time performance information about who is contributing and who is reaching the goal. It appears that performance information 
arouses group members the sense of social presence and spurs them to be competitive, inducing upward social comparison, which confirms Paulus and Brown's (2003) view on the role of external interventions in enhancing performance in short-term setting. However, as discussed earlier, our prior studies incorporated the quantity feedback only to create a larger pool of ideas based on the long-standing assumption (i.e., quantity breeds quality (Osborn, 1957)), not considering the quality feedback. As pointed out earlier, we have learned that the quantity performance feedback alone does not have enough restrictiveness to consistently control the performance behavior throughout the session. To be specific, the tendency of performance competitiveness from quality to quantity toward later stages of the idea generation session was observed. In the early stage, individual's performance behavior was guided by procedural rules and performance feedback created a competitive atmosphere by showing their performances real-time. However, as the session progressed, individuals had realized that performance feedback was based on the frequency of their contributions, not the quality of their efforts. As a result, taking advantage of anonymity in the form of pseudonymity, individuals in almost all groups exhibited a tendency of self-presentation ${ }^{3)}$ by capitalizing on ideas of which quality was low and even frivolous (i.e., junk comments4) (Hiltz and Turoff, 1985)) toward the later stages of the session. In sum, less restrictiveness of the new structural features, which did not differentiate the quality of efforts put forth to reward performance behaviors accordingly, induced an unintended consequence.

Similarly, the same pattern of performance behavior (from quality to quantity toward later stages of the idea generation session) (see table 1 below) was observed in Jung 2013 study (Jung, 2013). Approximately, up to the middle stage from the early stage, individuals' performance

Table 1. Number of Ideas Generated per Approximate 3-Minute Intervals by Interactive Five-Member Groups When Given Performance Feedback in a 10-Minute Session

\begin{tabular}{|c|c|c|c|}
\hline \multirow{2}{*}{} & \multicolumn{3}{|c|}{ Time } \\
\cline { 2 - 4 } & $\begin{array}{c}0 \sim 3.2 \mathrm{~min} \\
(200 \mathrm{sec} .)\end{array}$ & $\begin{array}{c}3.2 \sim 6.4 \mathrm{~min} \\
(200 \mathrm{sec} .)\end{array}$ & $\begin{array}{c}6.4 \sim 10 \mathrm{~min} \\
(200 \mathrm{sec} .)\end{array}$ \\
\hline Pseudonymity & & & \\
Quantity & 19.02 & 18.35 & 26.13 \\
Quality & 58.56 & 56.32 & 41.62 \\
\hline
\end{tabular}

3) A motive to look good, competent, and to be viewed positively in the presence of others (Parks and Sanna, 1999).

4) The goal of idea generation is to identify a few quality ideas and implement those. Thus, we refer junk comments to idea submissions of which quality is low and frivolous. 
The Effect of Real-Time Individual Process Performance Feedback on Computer-based Group Idea Generation

behaviors were maintained in good currency. However, toward the later stage of the session, individuals had realized that performance feedback was based on the frequency of their contributions, not the quality of their efforts. As a result, taking advantage of anonymity in the form of pseudonymity, individuals in almost all groups exhibited a tendency of self-presentation by capitalizing on ideas of which quality was low.

\section{Theoretical Framework}

As the goal of brainstorming is "the generation of as many quality ideas as possible," the task has quantity and quality dimensions. Thus, both quantity and quality of performance feedback are equally important to achieve the goal. Austin and Bobko (1985) note that "if quality were a crucial outcome [as in brainstorming], then not including a quality measure of performance leads to criterion deficiency" (p. 291). Prior studies also suggest high correlation between quantity and quality (i.e., quantity breeds quality) (Pinsonneault and Heppel, 1998). Thus, both dimensions (quantity and quality) of performance feedback seem equally important to achieve the goal. With quantity feedback alone, Hull (1943) succinctly notes that:

If two or more behavior sequences, each involving a different amount of energy consumption or work (W) [e.g., high quality vs. low quality ideas], have been equally well reinforced an equal number of times, the organism will gradually learn to choose the less laborious sequence leading to the attainment of the reinforcing state of affairs. (p. 294)

Learned industriousness theory (Eisenberger, 1992) suggests a dimensional learning; individuals learned quantity dimension of performance is rewarded and generalized effort more to this performance dimension than to quality dimension. In other words, performance evolved toward the less effortful of energy expenditure required for reinforcement (p. 249), actively manipulating the experimental context in order to attempt to receive the most positive self-evaluation (Parks and Sanna, 1999). This explains why self-improvement motive to get better is interrupted and replaced by self-enhancement motive to feel better (upward comparison on surface, but downward comparison in terms of quality) in our prior studies. As we recall no studies that examined the effect of quality feedback on performance in the context of idea generation, the conventional practice in prior studies was that quality of ideas was measured by domain specific experts after ideas were collected, leaving no chance to examine a quantity-quality feedback trade-off if any.

In order to accomplish this vision (i.e., to dramatically intervene the group interaction process), the current EBS technology needs to 
move its level to the next level (i.e., level 2). All techniques developed to reinforce (or eliminate) gains (or losses) to date fall into Level 1 EBS (and GDSS in general) (DeSanctis and Gallupe, 1987). Level 2 EBS aids a performance assessment and control model with precision (e.g., process chart), reducing uncertainty (unidentifiability and unevaluability) of idea contributions. A process chart (see figure 1 below) allows participants to monitor process variation by comparing new performance data to past performance data. The chart objectively shows the pattern of event (i.e., individual performances) in the temporal process. Therefore, we incorporate real-time visual quantity-quality performance feedback in a form of process feedback. This feedback visually displays individuals' performances two-dimensionally (quality for each idea vertically and quantity of ideas horizontally). In addition, as individuals' contributions accumulate, process performance feedback reveals performance histories by connecting the sequence of ideas in a time-series format, telling a story of individual's performance. At an individual level, past performance behavior has been widely recognized as one of the best predictors for future performance behavior. If a previous contribution scored high, the system pushes an individual to score consistently high. If not, the system also pushes an individual to perform better by showing others' performances. Furthermore, the process performance feedback encourages two-dimensional social comparison at a group level. In the comparison process, the self-improvement motive (the extent to which people compare themselves to others that are perceived to be performing better) induces upward social comparison to match the performance of the best group members for both quality and quantity of each idea. As a result, process performance feedback establishes a full control of performance behavior to be task-oriented, sustaining a true competitiveness until the end of the session.

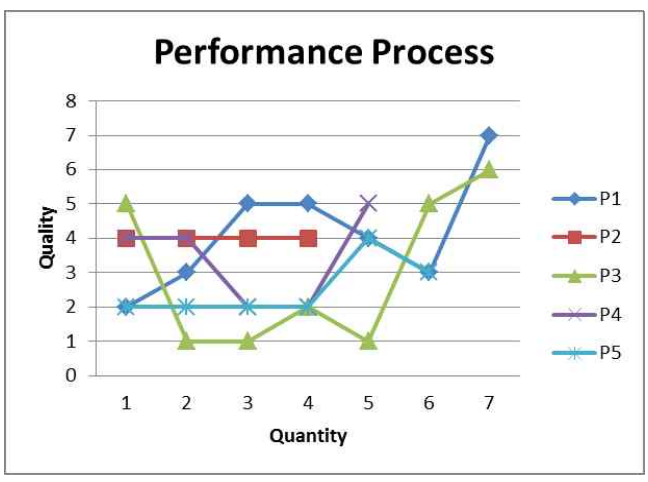

Figure 1. Example for Process Performance Feedback

H1: Groups in the pseudonymity condition will perform better than groups in the anonymity condition in terms of quantity of and quality score of ideas.

H2: Groups in the process performance feedback condition will perform better than groups in the non process performance feedback condition in terms of quantity of and quality score of ideas.

H3: Identifiability and Process Performance 
The Effect of Real-Time Individual Process Performance Feedback on Computer-based Group Idea Generation

Feedback will interact such that groups in the pseudonymity / process performance feedback condition will perform the best.

\section{Methods}

Since this study is a follow-up study of Jung et al.'s 2010 study, the same experimental method is replicated, except that the performance feedback method is modified to a process chart from a bar chart.

\subsection{Participants and Research Design}

A total of 100 undergrad business students (25 per each treatment) participated in the experimental sessions. The average participant age was 21.7 years and 56 percent were male. A $2 \mathrm{X} 2$ factorial design with group size five was used, crossing identifiability (i.e., anonymity versus pseudonymity) and process performance feedback (i.e., yes or no). Participants were randomly assigned to one of four treatment conditions.

\subsection{Task}

Participants were asked to generate ideas on “How can we improve the university's parking problem?" This task was chosen for its high relevance to the subjects - since it stimulates participants to draw on their personal knowledge and experience - and because it has been used in many prior studies (e.g., Connolly et al., 1990; Garfield et al., 2001).

\subsection{Operationalization of Quality Rating}

An information dashboard was designed and incorporated into the existing system to monitor all participants' performances. Two trained experts 5 ) who had been intensively exposed to idea generation task for at least two years were instructed to rate comments on the dashboard real-time. Participants in the feedback conditions were told that a built-in quality algorithm would rate comments based on a certain probability. This further controls any potential confounding effects in the experimental setting.

\subsection{Operationalization of Identifiability and Process Performance Feedback}

In order to generate pseudonyms for the Identifiability conditions, we collected a pool of pseudonyms, from which fifty gender-neutral terms were selected. Regarding Process Performance Feedback, we developed and deployed a real-time electronic visual representation of individual performances (See

5) To check the adequacy of the use of two experts, they independently rated quality of randomly selected 50 ideas from a master list complied during prior studies. The Cronbach's interrater reliability value of .892 indicated the coding was highly consistent. 


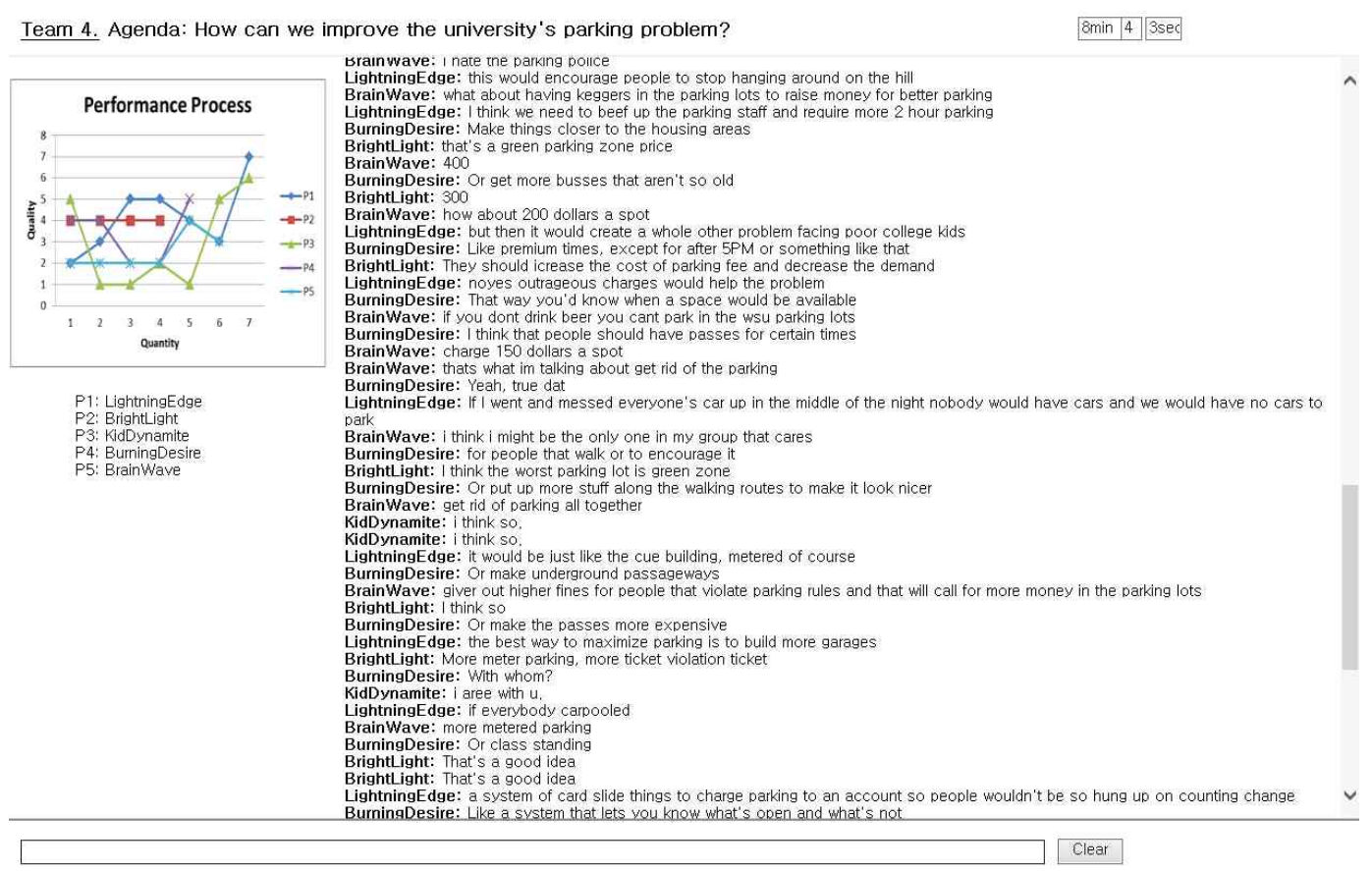

Figure 2. Example for Computer-Mediated Idea Generation Environment

Figure 2). The chart summarizes cumulative contributions each subject makes and allows the performance comparison with others in an assigned group and is redrawn every ten seconds based on their performances.

\subsection{Procedures}

On reporting to the experimental site, participants were assigned to a workstation in a computer classroom. Participants were instructed that they would work with other group members using a groupware system that would allow them to generate and exchange ideas. The subjects in the anonymity / no feedback condition were told that their contributions would be anonymous. The subjects in the anonymity / yes feedback condition were told that their contributions would be anonymous, but could evaluate each member's performance real-time. The subjects in the pseudonymity / no feedback condition were told that their contributions could be identified by the assigned pseudonyms. The subjects in the pseudonymity / yes feedback condition were told that their contributions could be identified by the assigned pseudonyms and they could evaluate each member's performance real-time. In addition, the subjects in the process performance feedback condition were told that a built-in quality algorithm would rate comments based on a certain probability, ranging idea quality from 1 (lowest) to 7 (highest). In fact, the trained experts 
-The Effect of Real-Time Individual Process Performance Feedback on Computer-based Group Idea Generation

were sitting in the other room, reading and rating comments real-time through the performance dashboard, which was hidden in the experimental room. All participants were invited and allowed to become familiar with the operation of the system prior to the main task by first working on a practice task. The experimenter then read aloud the experimental instructions to generate as many high quality ideas as possible while the participants followed in their own copies. Participants were also told that their contributions would be used as inputs to improve the campus parking problem. The system was programmed to stop automatically after 15 minutes, after which the participants completed a brief questionnaire, were debriefed, and released.

\subsection{Dependent Variables}

The dependent variables were quantity of and quality score of ideas. The manner by which these performance measures were operationalized is consistent with many prior studies (e.g., Connolly et al., 1990; Diehl and Stroebe, 1987). Additionally, the sum of the quality rating has been found to be the most reliable measure of idea quality (Diehl and Stroebe, 1987). Thus, the idea quality score was calculated by summing the quality scores of the ideas.

\section{Results}

Table 2 presents a summary of descriptive statistics. An alpha level of .05 was used for all statistical tests. Because the dependent variables quantity of ideas and quality score of ideas were highly correlated $(\mathrm{r}=925, \mathrm{p}<.001)$, a two-way MANOVA was utilized. Hypothesis 1, that groups in the pseudonymity condition will perform better than groups in the anonymity condition in terms of quantity of and quality score of ideas, was supported. A significant effect of identifiability was revealed (Wilks' $\Lambda=.503$, $\mathrm{F}(2,15)=7.402, \mathrm{p}<.05, \mathrm{n} 2=.497)$. The tests of between subjects effects indicated that the model is significant at $\mathrm{p}<.025$ for both quantity $(\mathrm{F}=$ $12.897, \mathrm{p}=.002)$ and quality $(\mathrm{F}=11.931, \mathrm{p}=$ $.003)$. Hypothesis 2, that groups in the process performance feedback condition will perform better than groups in the non-process performance feedback condition in terms of quantity of and quality score of ideas, was supported. A significant effect of process feedback was revealed (Wilks' $\Lambda=.167, F(2,15)$ $=37.419, \mathrm{p}<.05, \mathrm{n} 2=.833)$. The tests of between subjects effects indicated that the model is significant at $\mathrm{p}<.025$ for both quantity $(\mathrm{F}=$ $71.913, \mathrm{p}=.000)$ and quality $(\mathrm{F}=51.426, \mathrm{p}=$ $.000)$. Hypothesis 3, that identifiability and process performance feedback will interact such that groups in the pseudonymity / process performance feedback condition will perform the best, was supported. A significant interaction effect between pseudonymity and process feedback was revealed (Wilks' $\Lambda=.498, F(2,15)$ 
r정보시스템연구」제23권 제2호, 2014년 6월

Table 2. Means and Standard Deviations for Brainstorming Group Performance

\begin{tabular}{|c|c|c|c|}
\hline \multirow{2}{*}{$\begin{array}{c}\text { Dependent } \\
\text { Variable }\end{array}$} & \multirow{2}{*}{ Identifiability } & \multicolumn{2}{|c|}{ Process Performance Feedback } \\
\cline { 2 - 4 } Quantity & Pseudonymity & Yes & No \\
& $\mathrm{M}$ & 59.20 & 20.80 \\
& $\mathrm{SD}$ & 9.86 & 3.63 \\
& Anonymity & & 19.20 \\
& $\mathrm{M}$ & 37.00 & 4.66 \\
\hline \multirow{5}{*}{ Quality } & $\mathrm{SD}$ & 9.35 & \\
& Pseudonymity & & 46.39 \\
& $\mathrm{M}$ & 135.84 & 12.82 \\
& $\mathrm{SD}$ & 29.24 & 49.72 \\
& Anonymity & & 13.48 \\
\hline
\end{tabular}

$=7.555, \mathrm{p}<.05, \mathrm{n} 2=.502)$. The tests of between subjects effects indicated that the model is significant at $\mathrm{p}<.025$ for both quantity $(\mathrm{F}=9.662$, $\mathrm{p}=.007)$ and quality $(\mathrm{F}=14.937, \mathrm{p}=.001)$.

\section{Discussion}

This study attempted to examine a variation of performance feedback using a process chart due to the limitation observed in prior performance feedback study (e.g., Jung, 2010). Jung and colleagues exercised a quantity-based performance feedback only based on the dominant assumption (i.e., quantity breeds quality) in idea generation research. Under such quantity-based feedback, individuals learned that quantity dimension of performance is rewarded and generalized effort more to this performance dimension than to quality dimension. Therefore,
Jung and colleagues learned the necessity of not only quantity feedback but also quality feedback. However, there was a major technical hurdle to overcome before implementing such quantity-quality performance feedback system. To be specific, a real-time based quality feedback was considered not feasible in the idea generation experimental setting because a domain expert cannot monitor and rate all participants' incoming comments that quickly accumulate at a higher rate through parallel input. We recruited two trained experts, of which Cronbach interrater reliability value was high (alpha $=0.892)$, and applied a dual-rating system to overcome the limitation.

We then argued that the process performance feedback visually displays individuals' performances two-dimensionally (quality for each idea vertically and quantity of ideas horizontally) and encourages two-dimensional social comparison for both quantity and quality 
simultaneously. We hoped that upward social comparison would emerge in the comparison process to match with the best performer, sustaining competitiveness throughout the idea generation session. Our results showed that both Identifiability and Process Performance Feedback have an effect on performance enhancement. However, the process performance feedback showed a much stronger effect on performance. Furthermore, the result from hypothesis 3 evidences that Identifiability and Process Performance Feedback can interact and have a significant effect on performance enhancement. Taken the results together, the statistical outcomes suggest putting more weight on performance feedback in group interaction process. This indicates that although intrinsic motivation is an important factor in generating creative ideas, external motivation in the form of performance feedback plays a critical role in idea generation.

An interesting finding is that although the process feedback had an effect on performance enhancement, its magnitude is lower than expected when compared to that of quantity-based feedback (see table 3 below). Since the essence of information graphics is how to interpret graphics effectively so that it reveals the shape of the data in a comparative perspective, one reason might lies in the readability of the real-time process chart provided on the computer screen. The According to the anchoring framework that is developed to match data extraction tasks and graphical representations (Tan and Benbasat, 2000), it suggests a bar chart over a line chart when both $\mathrm{x}$ - and $\mathrm{y}$ - values need to be anchored high as in group performance feedback. Similarly, Simkin and Hastie's study (1987) also suggest a bar chart to be a suitable means for a comparison judgment task such as performance feedback. Thus, the performance comparison with a bar chart is rather simple to follow, whereas the performance comparison with a process chart seems to require some effort to follow (see figure 3 below). This leads to an avenue for research. Given that prior studies (Mullen, 1983; Shaw, 1981) consistently suggest approximately five as the most ideal group size in dealing with intellectual and cognitive tasks (e.g., idea generation), the results comparison between a process chart based performance feedback with group size 3, 4, and 5 and a bar chart based performance feedback with group size 3, 4, and 5 will yield better insight of the use of a process

Table 3. A performance comparison between two studies

\begin{tabular}{|c|c|c|c|}
\hline \multicolumn{2}{|c|}{$\begin{array}{c}\text { Quantity Performance Feedback } \\
\text { (Jung et al., 2010) }\end{array}$} & \multicolumn{2}{|c|}{ Quantity-Quality Performance Feedback Using a } \\
Process Chart
\end{tabular}




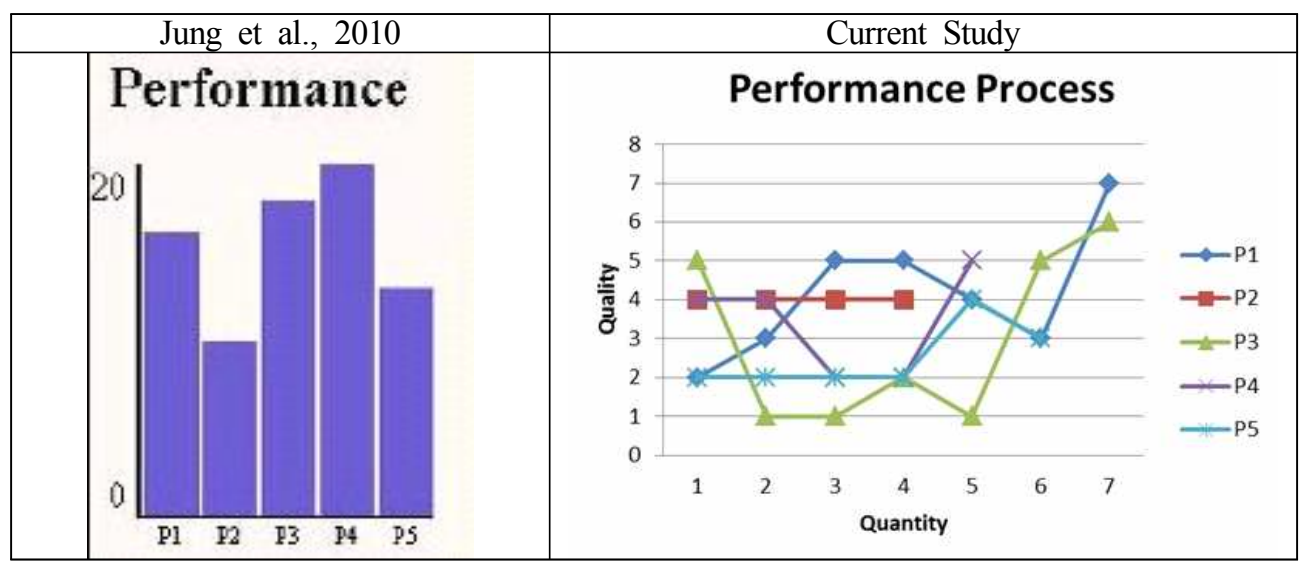

Figure 3. A Bar-Based Performance Chart Versus A Process-Based Performance Chart

chart.

Another avenue for research is to include the notion of goal setting into the process performance feedback. Locke and Latham (1990) conclude that goals or intentions can facilitate task performance as they motivate people to exert effort, encourage people to persist, and guide people's attitudes and direct their behavior to focus on the outcome. In other words, goals as a motivational technique provide standards for systematic self-evaluation, serving as a cue to regulate action by strengthening the linkage between effort (or motivation) and performance (see Locke and Latham, 1990). Whereas process performance feedback alone only establishes vague and general performance targets, quality goal setting establishes specific performance targets, which help individuals to evaluate their performance more accurately (McGregor, 1957; Nelson and Quick, 1996). Yet, without clear feedback, goal setting is less effective, as there is no objective mechanism to guide the individuals in the progress of their attempts to reach the goal (Luthans, 2002). Combined together, process performance feedback and goal setting would allow individuals to monitor the pattern of event (i.e., individual performances) and display performance deviations from the goal. Furthermore, patterns of interactions (i.e., sustained competitiveness) would emerge to achieve high-quality performance, which requires goals and quality monitoring to fully control their own work.

Like an adage "a picture is worth a thousand words," human brains process images better and more quickly than sets of words or numbers (Goncalves and Tavares, 1998). Despite widespread use of information graphics, which displays an organization's critical success factors in graphical formats on a single screen, Groupware - a collaborative software that has been recognized as a key driver of organizational performance - has failed to adopt the potentials of graphical formats in the idea generation stage to 
— The Effect of Real-Time Individual Process Performance Feedback on Computer-based Group Idea Generation

enhance group productivity. Davis et al. (1989) have suggested that the use of computing technologies (including Groupware) partially relies on usefulness perception. The usefulness concept involves the idea that users will perform more effectively. Since our studies including this study consistently demonstrate practical benefits of visual performance feedback on performance enhancement, examining the effect of other graphics, such as dot and line, in the context of computer-based idea generation in facilitating performance would be a practical implication.

Like any research undertaking, this study is limited in certain respects. There are obvious issues related to external validity. We employed a laboratory experiment with student participants in a simulated group idea generation environment. These participants also had no significant stake in the outcome. Although they understood the task and appeared to participate adequately, these individuals are not typical decision makers for this task domain. Yet, the task was germane to their situation as university students. In addition, the use of a group simulator moves away from a natural group setting. Nevertheless, while we may not be able to generalize our findings to all forms of group idea generation and all types of groups, we can probably generalize to groups of concerned participants asked to generate ideas on an issue that directly concerns them. Additional research is needed to understand the extent to which these findings may generalize to different environments, tasks, subject configurations, and contexts.

Acknowledgement: This work was supported by research grants from the Catholic University of Daegu in 2014.

\section{References}

Austin, J. T. and Bobko, P. "Goal setting theory: Unexplored areas and future research needs," Journal of Occupational Psychology, Vol. 58, 1985, pp. 289 308.

Ashford, S. J. and Cummings, L. L. "Feedback as an individual resource: Personal strategies of creating information," Organizational Behavior and Human Performance, Vol. 32, 1983, pp. 370.398. Cacioppo, J. T. and Petty, R. E. "The need for cognition," Journal of Personality and Social Psychology, Vol. 42, 1982, pp. $116-131$

Connolly, T. Jessup, L. M. and Valacich, J. S. "Effects of Anonymity and Evaluative Tone on Idea Generation in ComputerMediated Groups," Management Science, Vol. 36, 1990, pp. 689-703.

Davis, F. D. Bagozzi, R. P. and Warshaw, P. R. "User acceptance of computer technology: A comparison of two theoretical models," Management Science, Vol. 35,1989, 982-1003.

Dennis, A. R. Valacich, J. S. Connolly, T. and 
Wynne, B. E. "Process Structuring in Electronic Brainstorming, " Information Systems Research, Vol. 7, 1996, pp. 268-277.

DeSanctis, G. and Gallupe, R. B. "A foundation for the study of decision support systems," Management Science, Vol. 33, 1987, pp. $589-609$.

Diehl, M. and Stroebe, W. "Productivity Loss in Brainstorming Groups: Toward the Solution of a Riddle," Journal of Personality and Social Psychology, Vol. 53, 1987, pp. 497-509.

Eisenberger, R. "Learned Industriousness," Psychological Review, Vol. 99, 1992, pp. 248-267.

Garfield, M. J. Taylor, N. J. Dennis, A. and Satzinger, J. W. "Research Report: Modifying Paradigms - Individual Differences, Creativity, Techniques, and Exposure to Ideas in Group Idea Generation," Information Systems Research, Vol. 12, 2001, pp. 322-333.

Goncalves, P. C. T. and Tavares, J. M. R. S. "A GUI for a Software that Analyses a Composite Bolted Joint,” International Journal on Human-Computer Interaction. Vol. 1, 2008, pp. 25-41.

Hackman, J. R. and Morris, C. G. "Group tasks, group interaction process, and group performance effectiveness: A review and proposed integration," Advances in Experimental Social Psychology, Vol. 8,
1975, pp. 45- 99.

Hiltz, S. R. and Turoff, M. "Structuring Computer-Mediated Communication Systems to Avoid Information Overload," Communications of the $A C M$, Vol. 28, 1985, pp. 59-85.

Hull, C. L. Principles of Behavior. Appleton-Century-Crofts, 1943.

Jung, J. H. "The Effects of Objective Self-Awareness and Ostracism on Reducing Junk Comments in Computer-Based Idea Generation," Journal of Business Research, Vol. 25, 2010, pp. 313-336.

Jung, J. H. "The Effects of Frivolous Comments on the Performance of Computer-Mediated Group Idea Generation," Journal of Business Research, Vol. 27, 2012, pp. 195-217.

Jung, J. H. "Effect of Total-Identification on the Performance of Computer-Mediated Group Idea Generation," Journal of Business Research, Vol. 28, 2013, pp. 27-50.

Jung, J. H. Schneider, C. and Valacich, J. "Enhancing the Motivational Affordance of Information Systems: The Effects of Real-Time Performance Feedback and Goal Setting in Group Collaboration Environments," Management Science, Vol. 56, 2010, pp. 724-742.

Landry, C. and Bianchini, F. The Creative City, Demos, 1995. 
- The Effect of Real-Time Individual Process Performance Feedback on Computer-based Group Idea Generation

Luthans, F. Organizational Behavior. McgrawHill, 2002.

Nelson, D. L. and Quick, J. C. Organizational Behavior: The Essentials. West Publishing, 1996.

Locke, E. A. and Latham, G. P. A Theory of Goal Setting and Performance. Prentice Hall, Englewood Cliffs, 1990.

McGrath, J. E. Groups: Interaction and Performance, Prentice Hall, 1984.

McGregor, D. M. “An Uneasy Look at Performance Appraisal," Harvard Business Review, Vol. 35, 1957, pp. 89-94.

Michener, H. A. and DeLamater, J. D. Social Psychology(4th ed.), Harcourt Brace College Publisher, 1999.

Mullen, B. "Operationalizing the Effect of the Group on the Individual: A Self-Attention Perspective," Journal of Experimental Social Psychology, Vol. 19, 1983, pp. 295-322.

Nijstad, B. A. Diehl, M. and Stroebe, W. "Cognitive Stimulation and Interference in Idea-Generating Groups," in Group Creativity: Innovation Through Collaboration, Paulus, P. B. and Nijstad, B. A. (eds.), Oxford University Press, 2003, pp. 110-136.

Osborn, A. F. Applied imagination, Scribner, 1957.

Parks, C. D. and Sanna, L. J. Group performance and interaction, Westview Press, 1999.
Paulus, P. B. and Brown, V. R. "Enhancing Ideational Creativity in Groups: Lesson From Research on Brainstorming," in Group Creativity: Innovation Through Collaboration, Paulus, P. B. and Nijstad, B. A. (eds.), Oxford University Press, 2003, pp. 110-136.

Pinsonneault, A. and Heppel, N. "Anonymity in Group Support Systems Research: A New Conceptualization, Measure, and Contingency Framework," Journal of Management Information Systems, Vol. 14, 1998, pp. 89-108.

Porter, L. W. and Lawler, E. E. Managerial Attitudes and Performance. RD Irwin, Homewood, 1968.

Roy, M. C. Gauvin, S. and Limayem, M. "Electronic Group Brainstorming: The Role of Feedback on Productivity," Small Group Research, Vol. 27, 1996, pp. 215-247.

Shaw, M. E. Group Dynamics: The Psychology of Small Group Behavior, McGraw-Hill, 1981.

Simkin, D. and Hastie, R. "An InformationProcessing Analysis of Graph Perception," Journal of the American Statistical Association, Vol. 82, 1987, pp. 454-465.

Steiner, I. D. Group process and productivity. Academic Press, San Diego, 1972.

Tan, J. K. H. and Benbasat, I. "Processing of graphical information: a decomposition 
r정보시스템연구」제23권 제2호, 2014년 6월

taxonomy to match data extraction tasks

and graphical representation," Information

Systems Research, Vol. 1, 1990, pp.

416-439.

Valacich, J. S. Jung, J. H. and Looney, C. A. "The

Effcets of Individual Cognitive Ability and Idea Stimulation on Idea-Generation Performance," Group Dynamics:

Theory, Research, and Practice, Vol. 10, 2006, pp. 1-15.

VanGundy, A. B. Idea Power: Techniques and Resources to Unleash the Creativity in Your Organization, AMACOM, 1992.

\section{정종호(J. H. Jung)}

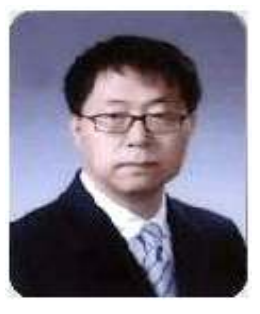

J. H. Jung is an associate professor in Information Systems in the College of Economics and Business at Catholic University of Daegu, South Korea. He received the $\mathrm{Ph} . \mathrm{D}$. degree in information systems from Washington State University. He has published in Group Dynamics, Management Science, Small Group Research, and among others. 


\title{
The Effect of Real-Time Individual Process Performance Feedback on Computer-based Group Idea Generation
}

\author{
Joung-Ho Jung
}

In computer-mediated idea generation where contributions can be anonymous, the ability to accurately monitor performances is limited, inducing social loafing. Prior research has suggested that social loafing is likely an important factor in reducing task performance. Researchers have theorized that loafing could be minimized if clear performance feedback is provided. Our prior study evidences a substantial performance gain by the provision of real time performance information about who is contributing and who is not. However, our prior study incorporated the quantity feedback only to create a larger pool of ideas based on the long-standing assumption (i.e., quantity breeds quality), not considering the quality feedback. As a result, taking advantage of anonymity in the form of pseudonymity, individuals in almost all groups exhibited a tendency of self-presentation by capitalizing on ideas of which quality was low and even frivolous (i.e., junk comments) toward the later stages of the session. Thus, we have learned that the quantity performance feedback alone does not have enough restrictiveness to consistently control the performance behavior throughout the session. Since a process chart allows participants to monitor process variation by comparing new performance data to past performance data, we incorporated real-time visual process performance feedback to reveal performance histories by connecting the sequence of idea quality scores in a time-series format. Using this environment, a laboratory experiment was conducted with five-member groups that examined the influence of both identifiability (i.e., anonymity versus pseudonymity) and process performance feedback (i.e., yes or no) in a $2 \times 2$ factorial design. The result showed that groups in the process performance feedback treatment outperformed groups in the no feedback treatment. Additionally, process performance feedback and identifiability interacted such that groups in the process performance feedback / pseudonymity treatment had the highest performance. The implications of these findings for future research, as well as the implications for the design of group idea generation procedures are discussed.

Keywords: Idea Generation, Process Performance Feedback

* 이 논문은 2014년 6월 1일 접수하여 2차 수정을 거쳐 2014년 6월 24일 게재 확정되었습니다. 